\title{
El vídeo como estrategia didáctica en la educación superior.
}

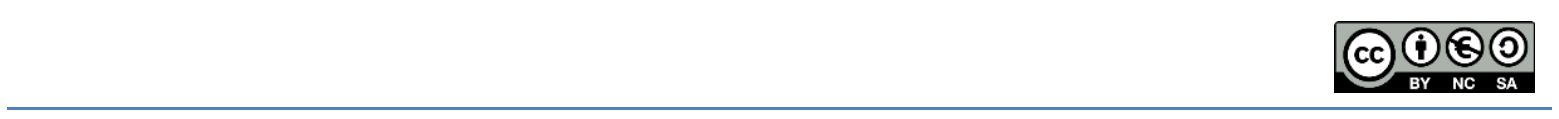

The video as a teaching strategy in higher education.

Ing. Javier Salazar Mera Mg. ${ }^{1}$, Licda. Estefanía Sánchez Nùñez. ${ }^{2}$, Efraín Velasteguí López Mg. ${ }^{3}$, Licda. Silvia Núñez Acosta. ${ }^{4}$

\begin{abstract}
.
DOI: https://doi.org/10.33262/cienciadigital.v2i2.71

The use of video as a support tool in the teaching-learning process is an innovative strategy that can be used inside and outside the classroom, in order to reinforce and obtain new knowledge through documentaries, tutorials, films or short films. This research is based on determining the use of video by the teacher in the Faculty of Human Sciences and Education of the Technical University of Ambato, this being a faculty that has the appropriate technological resources for the reproduction and production of videos. The research was conducted with a sample of 74 educators in the Faculty of Human Sciences and Education; with the results obtained it is observed that most teachers use video as a computer resource to support the teaching learning process (PEA).
\end{abstract}

Keywords: Video, Strategy, PEA, Tool, Higher Education.

\section{Resumen.}

El uso del video como una herramienta de apoyo en el proceso enseñanza aprendizaje es una estrategia innovadora que se puede utilizar dentro y fuera del aula de clase, con el fin de reforzar y obtener nuevos conocimientos ya sea mediante documentales, tutoriales, películas o cortometrajes. Esta investigación se basa en determinar el uso

1 Universidad Técnica de Ambato Facultad de Ciencia de la educación Ambato, Ecuador. jsalazar@uta.edu.ec

2 Universidad Técnica de Ambato Facultad de Ciencia de la educación Ambato, Ecuador. estefysanchez13@gmail.com

3 Universidad Técnica de Cotopaxi, Faculta de Sistemas Informáticos, Cotopaxi, Ecuador, luis.velastegui7838@utc.edu.ec

${ }^{4}$ Unidad Educativa Juan Montalvo, Ambato, Ecuador, silvidanz@hotmail.com 
del video por parte del docente en la Facultad de Ciencias Humanas y de la Educación de la Universidad Técnica de Ambato, siendo esta una facultad que cuenta con los recursos tecnológicos adecuados para la reproducción y producción de videos. La investigación se realizó con una muestra de 74 educadores en la Facultad de Ciencias Humanas y de la Educación, con los resultados obtenidos se observa que la mayoría de docentes utilizan el video como un recurso informático como apoyo al proceso enseñanza aprendizaje (PEA).

Palabras Claves: Video, Estrategia, PEA, Herramienta, Educación Superior.

\section{Introducción.}

Las tecnologías de información y comunicación están inmersas cada vez más en la educación siendo una influencia positiva en el aprendizaje de los estudiantes y un apoyo para el docente en la construcción y desarrollo del currículo. La escasa utilización de los medios audiovisuales en el aula de clase implica que la enseñanza continúe siendo tradicional sin oportunidad para docentes y estudiantes de mejor la calidad del aprendizaje.

Bachman \& Harlow (2012) expone que el vídeo es la exposición de una cifra de imágenes por segundo, que generan en el espectador la impresión de movimiento, es considerado como una multimedia educativa ya que el alumno lleva el proceso a su ritmo y tiene la independencia para empezar un autoaprendizaje. La educación de esta época lleva a los docentes a buscar estrategias nuevas como el video para impulsar el aprendizaje de manera autónoma y colaborativa en los estudiantes (Sarmiento, May, Cadena, \& Casanova, 2015).

El video también llamado videograma es uno de los medios didácticos que se pueden aplicar en la educación con una adecuada utilización para facilitar a los docentes la transferencia de conocimientos y a los estudiantes la asimilación de los mismos, el objetivo que cumple el video es llegar a las metas propuestas. Los videogramas tienen la utilidad de reforzar los contenidos de las clases impartidas por medio de distintas metodologías, en el proceso enseñanza-aprendizaje la transmisión de la información de educador a alumno es una ayuda para la comprobación del aprendizaje (L. Bravo, 1996).

El vídeo es un instrumento muy útil que se acopla a las necesidades de cada individuo, los estudiantes que no pueden asimilar toda la explicación del docente pueden ayudarse por medio de varias repeticiones de un video hasta completa el conocimiento. Este se ajusta a todos los contenidos y actividades que el educador realiza en el aula de clase (Ros \& Rosa, 2014). 
El video está ligado con las instituciones educativas transformando el proceso de enseñanza para lograr mejores resultados en la educación. Permite insertar contenidos que se ajusten a las necesidades de cada educar, trabando a un ritmo propio con el fin de llegar a ser una forma útil de retroalimentación, adecuado para los estudiantes que no son hablantes nativos. El video llegara a emplazar al libro de texto, transformando la entrega de contenido donde activará el aprendizaje activo de los estudiantes (Summary, 2015).

El objetivo principal de esta investigación es determinar los pasos para la elaboración del video mediante la búsqueda de un software adecuado, la realización de encuestas, consultas en base de datos y pruebas de grabación y edición, generando en los docentes una destreza para el uso del video en la educación superior.

\section{Metodología.}

Se realizará dos modalidades de investigación, la de campo y bibliográfica. De campo porque el estudio se lo ejecutara en las instalaciones de la Facultad de Ciencias Humanas y de la Educación donde los docentes están trabajando; y bibliográfica porque se utilizará información de la base de datos de la universidad para determinar población y muestra así como también libros y paper que se encuentran disponibles en la biblioteca y en el repositorio digital de la Facultad.

En un primer momento la investigación será de tipo exploratorio hasta determinar las características a investigar como son tipo de video, métodos de enseñanza, población, entre otros; luego, la investigación será descriptiva a medida que se vaya desarrollando las categorías fundamentales y a constelación de ideas; finalmente, se realizara una asociación de variables.

Población y muestra.- Está conformada los decentes de la de la Facultad de Ciencias Humanas y de la Educación de la Universidad Técnica de Ambato.

Cuadro 1: Población y muestra.

\begin{tabular}{lc}
\hline \multicolumn{1}{c}{ Docentes } & Número \\
\hline Nombramientos & 36 \\
Nombramiento provisional & 3 \\
Docentes ocasionales & 45 \\
Técnicos docentes & 6 \\
Suman & 90 \\
\hline
\end{tabular}

Elaborado por: Grupo de Investigación.

Como la población de docentes varia para cada semestre electivo de acuerdo con la disponibilidad de contratos, se tiene una variabilidad tanto en número de personas como en 
el tipo de profesional que requiere la institución, motivo por el cual se procede a calcular una muestra representativa, utilizando la siguiente expresión:

$\mathrm{n}=$ tamaño de la muestra.

$\mathrm{K}=$ constante del error.

p = Proporción de la población con la característica deseada (éxito).

q = Proporción de la población sin la característica deseada (fracaso).

$\mathrm{E}=$ Error experimental.

$\mathrm{N}=$ tamaño de la población.

$$
\begin{gathered}
\mathrm{n}=\frac{\mathrm{N}(\mathrm{pq})}{(N-1)\left(\frac{E}{K}\right)^{2}+(p q)} \\
\mathrm{n}=\frac{90(0.5 * 0.5)}{(90-1)\left(\frac{0.05}{2}\right)^{2}+(0.5 * 0.5)} \\
\mathrm{n}=73,6 \\
\text { Muestra }=74 \text { docentes }
\end{gathered}
$$

La variable independiente de la investigación es video un sistema que permite la grabación de imágenes y sonidos en medios magnéticos que luego pueden ser editados y reproducidos por diferentes tecnologías.

La variable dependiente de la investigación es la educación que es el proceso de transferencia de conocimientos, habilidades, valores, creencias y hábitos de un grupo de personas a otras personas, utilizando diferentes estrategias.

El video en la educación transmite emociones y señales no verbales directas proporcionando la libertad a los estudiantes de observar los acontecimientos a su manera, los temas basados en textos no tienen esta posibilidad es por ello que los estudiantes de la generación X pueden tener dificultades para aprender de los contenidos fundamentados en texto estático (De Leng, Dolmans, Van De Wiel, Muijtjens, \& Van Der Vleuten, 2007). 
El uso del video en la en la enseñanza es estimado de manera positiva ya que es un refuerzo para el aprendizaje, teniendo muchas ventajas en el proceso de instrucción donde ayuda en los estudios a los alumnos y motiva en la asimilación de contenidos de las diferentes áreas impartidas (Sánchez \& Martínez, 2014).

Gutiérrez y Villarreal (2008) enuncian tres etapas para la producción de un video: preproducción, producción y posproducción.

Preproducción. - Es la etapa donde se prepara todo para la grabación del video desde la idea hasta los últimos detalles de edición para ello se realiza un plan de producción con los siguientes elementos: equipo humano, equipo técnico y escaleta o guion.

Equipo humano: Se realiza una lista de todas las personas que van a participar en el video ya se la persona que va a grabar o los actores en caso que los haya.

Equipo técnico: Todos los materiales que se van a ocupar en la grabación los enlistamos con el fin de que el video tenga un excelente resulta visual.

Escaleta o guion: Con el fin de redactar todo lo que le corresponde hacer al personal se narra un guion a cerca de lo que se presenta visual mente, para ello es importante mencionar los cuatro elementos básicos para formar una historia; los personajes para que realizan las acciones, las acciones para saber el cambio y el movimiento del primer elemento, el lugar para ubicación de un contexto y el tiempo el cual se compone por tres tipos, tiempo en que transcurre la historia, tiempo total de la historia, tiempo real de la historia.

Producción. - Es más que prender la cámara y grabar, hay que tener presente el lugar de grabación, la composición, la iluminación, el sonido y la escenografía.

Composición: El camarógrafo debe hacer pruebas de cámara para visualizar la calidad de la imagen, y ser creativo con los movimientos de las personas a quien está grabando para captar todos los detalles.

Iluminación: Las luces deben estar en una posición adecuada de tal manera que la calidad de la imagen sea apropiada para la visualización de la audiencia, de tal manera que se pueda apreciar el color, forma y brillo de los objetos y de los personajes.

Sonido: Es muy importante que video cuente con un buen audio, para ello los micrófonos son lo primordial y deben estar ubicados a una distancia apropiada de manera que se pueda escuchar las voces claras.

Escenografía: Debe ser de agradable para la audiencia, aquí está implícito la iluminación, el aspecto del escenario en el que va hacer la grabación y vestimenta que van a llevar los 
personajes del video.

Posproducción. - Después de haber realizado la toma de escenas para el video la siguiente etapa es la edición donde revisamos las cuestiones técnicas, el software necesario, los efectos especiales y el ritmo.

Ritmo: Para que la edición del video se adecuada debemos tomar en cuenta el tiempo que existe entre una toma y otra, la duración de los planos va de depender de qué tipo de video o información deseemos transmitir, si vamos a incluir un video una fotografía o sonido.

Edición: Es parte primordial de la posproducción ya que podemos editar independientemente las imágenes que vamos a insertar, el audio y los videos. Recortar, separar, insertar efectos, texto, sonidos e instrucción es parte de esta etapa.

Zettl (2009) expresa en su libro seis instrumentos importantes para la producción de los videos de televisión: cámara, iluminación, audio, switcher, grabadora de video y edición en posproducción.

Cámara. - Es el elemento más importante, el cual se pude obtener de distintos tamaños y formatos; pueden ser pequeñas que caben en la mano o de un tamaño considerable que necesitan un soporte para poderlo mover.

Iluminación. - para que la cámara pueda percibir de una manera eficaz los objetos la iluminación debe ser adecuada y manipulada hasta llegar a una exactitud ya que la cámara no puede ver por debajo de cierto nivel e luz. Los spots de las luces deben ser apropiados de manera que se puedan subir o bajar para nivelar el brillo.

Audio. - Es muy importante que en el video exista un audio nítido para crear un ambiente con la audiencia, en la producción de sonido el micrófono es primordial porque convierte las ondas de sondo en señales de audio, para las múltiples actividades como conciertos, noticieros o juegos de deportes se necesitan distintos micrófonos para capturar mejor el sonido.

Switcher.- Es el panel de control de video que permite escoger entre varias fuentes la mejor para una edición instantánea. Cumple 3 funciones importantes: escoger una fuente adecuada de video en varias entradas, ejecutar transiciones primordiales entre dos fuentes de video y crear o recobrar efectos especiales como la división de pantalla.

Grabadoras. - La mayoría de los programas de televisión son grabados y almacenados para después transmitirlo para ello existen dos tipos: grabación en cinta y sistema sin cinta; la grabación en cinta aún se utiliza ya que los sistemas de videograbación antigua manipulan videocaseteras; el sistema sin cinta se utilizan discos duros para almacenar los videos así como la edición y recuperación de los mismos. 
Edición en posproducción. - Es la apariencia simple que tienen los videos antes de ser editados. La edición no línea se hacer por medio de un software en el computador después de haber almacenado los videos en un disco duro. La edición lineal requiere de videograbadoras de donde se pude obtener el material original grabado con las cámaras.

\section{Software con licencia.}

Camtasia Studio. - Son programas con licencia pagada, creados por la empresa TechSmith Corporation para edición de los diferente archivos de video (AVI, MP4, WMV, MOV, entre otros), y grabación de pantalla. Su interfaz asta diseñada con una línea de tiempo de variadas pistas donde podemos añadir imágenes, música, videos, narraciones, fotos y más. Cuenta con animaciones de textos, efectos especiales para las imágenes y con resolución en los videos hasta de 4000 píxeles (4K); también contiene una gran galería de fondos animados, pistas de canciones libres para utilizar en YouTube o Vimeo, iconos animados y gráficos en movimiento ("Video Editor \&amp; Video Editing Software | Camtasia | TechSmith," 1995).

Wondershare Filmora.- Es un editor de videos creado por Wondersahre Technology, tiene un diseño intuitivo y es muy fácil de utilizar, consta de funciones creativas como: texto, filtros, música, transiciones y elementos de movimientos; exporta y edita videos en $4 \mathrm{k}$ y GIF; podemos importar imágenes, videos, y audio desde las redes sociales; así mismo se puede editar audios por medio del mesclador ("Filmora Wondershare Video Editor(Win\&amp;Mac)," 2016).

VideoStudio Pro X10.5.- En su última modificación agregaron la edición completa de videos en $360^{\circ}$, admite formatos multitudinarios en HD y $4 \mathrm{~K}$, cuenta con plantillas para editar o la línea de tiempo para combinar fotos, videos y audio en varias pistas ya sea importados o propios del programa, los efectos se pueden editar para lograr el aspecto exacto que se desee, se puede cargar los videos directamente a las redes sociales o guardarlos en un dispositivo de almacenamiento ("Software de edición de video de Corel VideoStudio Pro X10,” 2017).

Windows Movie Maker.- Es un componen de Windows desde la versión número 7 que sirve la para la edición y producción de videos con herramientas útiles con animaciones de transiciones, asustes del eje de tiempo, inserción de títulos y notas, efectos especiales, puede añadir música, videos, imágenes y voz. En las últimas versiones está diseñado para la edición el código XLM ("Windows Movie Maker,” 2016).

Premiere Pro CC.- Es un software de edición de video que permite importa archivos desde cámaras o teléfonos, recorta clips, añade títulos y perfecciona el audio. Es el único editor no línea ya que podemos colaborar en un proyecto y seguir trabajando en otro al mismo tiempo. Trabaja con material de archivos en distintos formatos, desde $8 \mathrm{~K}$ hasta realidad 
virtual, podemos combinarlo con otros productos como: Creative Cloud, Dynamic Link, After Effects, Illustrator, Photoshop y Adobe Media Encoder ("Adobe Premiere Pro CC | Software de edición y producción de vídeo,” 2017).

PowerPoint.- Forma parte de las herramientas de Microsoft Office que sirve para realizar presentaciones animadas, nos permite incluir imágenes, videos, audio; además podemos editar videos de forma limitada: brillo, contraste, recorte del video y la imagen ("¿Qué es PowerPoint? | PPT," n.d.).

\section{Software libre.}

OpenShot Video Editor.- Es un editor de videos multiplataforma con soporte para Windows, Max, Linux. Establecido con más de 70 idiomas, diseñado con una interfaz fácil y amigable para los usuarios, cuenta con animaciones en $3 \mathrm{D}$, edita audio con formas de onda, elimina fondos de videos, se puede insertar las capas que se desee para videos de fondo, pistas de audio, filigranas, entre otros ("OpenShot Video Editor," 2017).

VirtualDub.- Es un software gratuito para la edición de videos en Windows, tiene una interfaz simple, puede procesar grandes cantidades de archivos; está diseñado primordialmente al procesamiento de archivos AVI, pero también se puede utilizar MPEG1 , con referente a las imágenes se puede trabajar con BMP, captura vides de pantalla del computador, consta con un medidor de volumen e histograma para mecanizar el video de entrada ("Funciones De," n.d.).

CineFX.- Es un software gratuito de código abierto, se puede crear mundos virtuales de una manera fácil y sencilla, se puede ejecutar en Windows, Linux y OsX, cuenta con líneas de tiempo por cada objeto, sistema de efectos de partículas, motor de física con colisiones, múltiple luces con sombras, se puede publicar en la web con Interfaz de programación de aplicaciones (API) en JadWorld ("ReInventar Hollywood," n.d.).

Avidemux.- Es un editor de video de código abierto con licencia gratuita, se puede ejecutar en Linux, BSD, Mac OS X y Microsoft Windows, podemos realizar tareas simples como recortar, codificar y filtrar (Jes $\tilde{A}^{0}$ s Antonio Fern $\tilde{A}_{j}$ ndez Olmedo, 2014a).

VideoPad.- Es un programa para crear videos en Windows y MAC, consta de una versión gratuita, edición en 3D y conversión estereoscópica en 2D-3D, produce videos en pantalla verde para croma, se puede añadir videos, imágenes, audios o hacer nuestras propias pistas, cuenta con una biblioteca de sonidos gratuita, es compatible con algunos complementos

para añadir variedad de herramientas y efectos, captura videos desde la cámara o de diferentes dispositivos de vídeo ("VideoPad, editor de vídeo," n.d.)

Lightworks.- Es un software de edición de video con una versión gratuita, la única 
restricción son los formatos de salida, cuenta con una interfaz sencilla e intuitiva, con una línea de tiempo que da paso directo a efectos asombrosos y música de producción original, edición multicam, establece estándares para los recortes, trabaja con Boris Fx (plug-in de nivel avanzado) y efectos de texto con Graffitti, incluye paquetes de idiomas y se puede realizar trabajos colaborativos en tiempo real ("Lightworks," 2017).

\section{Editores en línea.}

Para hacer uso de los editores de video en línea es importante crear una cuenta en la plataforma que deseemos ocupar, es un requisito indispensable para hacer uso de las herramientas cada uno de ellos nos presenta.

WeVideo.- Es un editor de video en línea con versión gratuita y pagada, la versión sin paga inserta una marca de agua, permite subir los proyectos que realizamos en la nube, se pueden crea videos de forma colaborativa, combina más de 600 formatos de imágenes, audio y video, funciona en cualquier navegador de ordenadores incluso Mac, IOS, dispositivos Andriod y Chromebook, la resolución llega hasta 4K, permite grabar videos mientras navega en la web ("WeVideo," 2017).

Youtube.- Es un servidor de internet donde podemos compartir y visualizar videos. Desde el 2012 cuenta con la opción de edición en línea gratuita, algunas de sus características: agregar clips, en opción mejoras se puede recortar partes del producto que se está editando, ajustar el color, estabilizar movimientos, aplicación de filtros, existe la biblioteca de audio de youtube donde podemos hacer uso de ellos con sonidos gratuitos ("Editor de video de YouTube," 2017).

PowToon.- Es una herramienta muy útil donde podemos crear presentaciones y videos animados. Cuenta con plantillas pagadas y gratuitas, podemos importar imágenes, video, audio y utilizar la galería (Upcott, Rickeston, Kinving, \& Sullivan Gillian, 2017).

Kizoa.- Es un editor en línea de fotos y videos. Para editar vídeos es fácil su utilización y permite cortar en secuencias, aplicar efectos especiales, incluir transiciones, y agregar su propia música para resultados extraordinarios (“Editar Videos Gratis - Kizoa,” 2017).

Magisto.- Es una herramienta en línea que nos permite mejorar los videos que ya tenemos editados, e 3 simples pasos: subimos el video y las fotos que vamos a necesitar, elegimos un estilo y la banda sonora de la biblioteca, y por último los fabricantes analizar y mejoraren el video (Boiman, Ravacha, Dagan, \& Genauer, 2017).

\section{Resultados.}

Pregunta 1.- ¿Utiliza el celular o la cámara digital para capturar imágenes, videos o audio? 
Cuadro 2: Uso de dispositivos digitales para captura de imágenes.

\begin{tabular}{ccc}
\hline \multirow{2}{*}{ Alternativas } & \multicolumn{2}{c}{ Frecuencia } \\
& $\#$ & $\%$ \\
\hline Siempre & 23 & 31,08 \\
A veces & 40 & 54,05 \\
Nunca & 11 & 14,67 \\
Suman & 74 & 100 \\
\hline
\end{tabular}

Elaborado por: Grupo de Investigación.

Pregunta 2.- ¿Realiza edición de videos con imágenes o sonidos que capturó con el celular o la cámara digital?

Cuadro 3: Edición de videos con imágenes y sonidos capturados.

\begin{tabular}{ccc}
\hline \multirow{2}{*}{ Alternativas } & \multicolumn{2}{c}{ Frecuencia } \\
& $\#$ & $\%$ \\
\hline Siempre & 12 & 16,2 \\
A veces & 40 & 54,1 \\
Nunca & 22 & 29,7 \\
Suman & $\mathbf{7 4}$ & $\mathbf{1 0 0}$ \\
\hline
\end{tabular}

Elaborado por: Grupo de Investigación.

Pregunta 3.- ¿Qué software utiliza para realizar videos?

Cuadro 4: Software de edición de videos.

\begin{tabular}{lcc}
\hline \multicolumn{1}{c}{ Alternativas } & \multicolumn{2}{c}{ Frecuencia } \\
& $\#$ & $\%$ \\
\hline Adobe Premier & 3 & 3,7 \\
Camtasia & 9 & 11 \\
Open Shot & 2 & 2,4 \\
Virtual Dub & 0 & 0 \\
We Video & 3 & 3,7 \\
Windows Movie Maker & 20 & 24,4 \\
You Tube & 42 & 51,2 \\
Otros & 3 & 3,7 \\
Total & $\mathbf{8 2}$ & $\mathbf{1 0 0}$ \\
\hline
\end{tabular}

Elaborado por: Grupo de Investigación. 
Pregunta 4.- ¿Utiliza alguna metodología para realizar videos?

Cuadro 5: Utilización de metodología para realizar videos.

\begin{tabular}{ccc}
\hline \multirow{2}{*}{ Alternativas } & \multicolumn{2}{c}{ Frecuencia } \\
& $\#$ & $\%$ \\
\hline Siempre & 11 & 14,9 \\
A veces & 44 & 59,5 \\
Nunca & 19 & 25,7 \\
Suman & $\mathbf{7 4}$ & $\mathbf{1 0 0}$ \\
\hline
\end{tabular}

Elaborado por: Grupo de Investigación.

Pregunta 5.- ¿Utiliza los videos que se encuentra colgados en la web como: YouTube, Vimeo o redes sociales?

Cuadro 6: Utilidad de los videos colgados en la red.

\begin{tabular}{ccc}
\hline \multirow{2}{*}{ Alternativas } & \multicolumn{2}{c}{ Frecuencia } \\
& $\#$ & $\%$ \\
\hline Siempre & 29 & 38,7 \\
A veces & 43 & 57,3 \\
Nunca & 3 & 4 \\
Suman & $\mathbf{7 4}$ & $\mathbf{1 0 0}$ \\
\hline
\end{tabular}

Elaborado por: Grupo de Investigación.

Pregunta 6.- ¿Utilizaría actividades que incluyen videos como estrategias para enseñar?

Cuadro 7: Videos como estrategia para la enseñanza.

\begin{tabular}{ccc}
\hline \multirow{2}{*}{ Alternativas } & \multicolumn{2}{c}{ Frecuencia } \\
& $\#$ & $\%$ \\
\hline Siempre & 39 & 52,7 \\
A veces & 35 & 47,3 \\
Nunca & 0 & 0 \\
Suman & $\mathbf{7 4}$ & $\mathbf{1 0 0}$ \\
\hline
\end{tabular}

Elaborado por: Grupo de Investigación. 
Fig. 6. Videos como estrategia para la enseñanza.

Pregunta 7.- ¿Le gustaría utilizar videos como instrumento de evaluación?

Cuadro 8: Videos como instrumento de evaluación.

\begin{tabular}{ccc}
\hline \multirow{2}{*}{ Alternativas } & \multicolumn{2}{c}{ Frecuencia } \\
& $\#$ & $\%$ \\
\hline Siempre & 14 & 18,9 \\
A veces & 59 & 79,7 \\
Nunca & 1 & 1,4 \\
Suman & $\mathbf{7 4}$ & $\mathbf{1 0 0}$ \\
\hline
\end{tabular}

Elaborado por: Grupo de Investigación.

\section{Discusión.}

Según los datos del cuadro 2 el 31,08\% de los docentes siempre utilizan un dispositivo móvil, mientras que el 54,05\% lo hacen a veces y apenas un $14,67 \%$ no utilizan.

Son pocos los docentes que no utilizan dispositivos móviles para capturar imágenes y sonido ya que su edad tecnológica no les permite estar familiarizados con las actividades que se pueden realizar con las nuevas tecnologías.

Según los datos del cuadro 3 el 54,1\% de los docentes a veces realizan edición de videos con las imágenes capturadas con dispositivos digitales, pero el 29,7\% nunca realizan edición de videos y un 16,2\% siempre realizan la edición de videos.

Los docentes no siempre realizan la edición de videos ya que su tiempo de trabajo es prolongado, en casos los trabajos de los estudios de maestrías o PH ocupan el 100\% de su tiempo libre y en otros casos las tareas del hogar cubren el tiempo sobrante.

Según el cuadro 4 los docentes utilizan un 51,2\% el YouTube para la edición de videos, el 24,4\% opta por el software Windows Movie Maker, el 11\% prefiere editar con Camtasia Studio, apenas un 3,7\% elige Adobe Premier, de la misma manera es utilizado We Video con el 3,7\%, así como otros softwares de edición, así mismo un 2,4\% prefiere Open Shot y por último el 0\% de los encuestados no opta por Virtual Dub.

La mayoría de docentes utiliza YouTube y Movie Maker para la edición de videos ya que son softwares gratuitos q sencillos de utilízalos, muy pocos optan por los softwares pagados por su costo es elevado, o porque requiere un aprendizaje extra para ser manipulados. 
Según el cuadro 5 el 59,5\% de los docentes encuestados a veces utilizan metodologías para realizar videos, mientras que el 25,7 nunca optan por metodologías y el 14,9\% siempre ocupan metodologías en la edición de videos.

La cuarta parte de los encuestados no utilizan metodologías para realizar videos debido al tiempo y la escasa información de metodologías para la edición de videos.

Según el cuadro 6 el 57,3\% de los docentes encuestados a veces utilizan videos colgados en la red como por ejemplo YouTube y Vimeo, el38,7\% lo hacen siempre, mientras que el 4\% nunca opta por visualizar videos de la red.

Un pequeña parte de docentes encuestados no utilizan videos colgados en la red debido al tiempo limitado que tienen para realizar sus actividades extracurriculares.

Según el cuadro 7 el 52,7\% de los docentes encuestados respondieron que siempre les gustaría utilizar los videos como estrategia de enseñanza, mientras que el 47,3\% restante manifestaron que a veces usarían y no hubo ninguna respuesta de que nunca les gustaría utilizar esta estrategia.

Los docentes encuestados no siempre utilizaron el video como herramienta de enseñanza ya no se puede utilizar esta estrategia permanentemente porque existen temas que son teóricos y se deben usar otras estrategias que vayan acorte a la temática.

Según el cuadro 8 el 79,7\% de los docentes encuestados a veces les gustaría utilizar el video como instrumento de evaluación, el 18,9\% respondieron que a veces y el 1,4\% restante optaron que nunca harían uso.

Un mínimo número de docentes encuestados no les gustaría utilizar el video como instrumento de evaluación ya que las clases toma un sentido tradicionalista y hacen uso de estrategias innovadoras que motiven a los estudiantes.

\section{Conclusiones.}

- La mayor parte de docentes utilizan el celular para capturar imágenes y sonidos con el celular y la cámara digital.

- La mayoría de los docentes utilizan las imágenes capturadas para realizar la edición de videos.

- El software más utilizado por los docentes para la edición de videos son aquellos que se encuentra en línea y son gratuitos como el YouTube, Open Shot, We Video y Windows Movie Maker.

- La cuarta parte de los docentes no utilizan una metodología para realizar la edición de videos.

- Una pequeña parte de docentes encuestados no utilizan los videos colgados en la red como por ejemplo YouTube y Vimeo. 
- La mayoría de docentes encuestado optaron porque si les gustaría utilizar el video como estrategia de enseñanza.

- A la mayoría de docentes si les gustaría utilizar el video como instrumento de evacuación.

\section{Referencias bibliográficas.}

Microsoft Office. ¿Qué es PowerPoint? | PPT. (n.d.). Retrieved January 15, 2018, from https://products.office.com/es-mx/what-is-powerpoint

Filmora Wondershare Video Editor(Win\&amp;Mac) | Download Video Editing Software. (2016). Retrieved November 1, 2017, from https://filmora.wondershare.com/video-editor/

Boiman, O., Ravacha, A., Dagan, T., \& Genauer, R. (2017). Video Maker Features Content Marketing by Magisto. Retrieved November 3, 2017, from https://www.magisto.com/video-marketing?prev_path=/\&via=top_menu

Bravo, L. (1996). ¿Qué es el vídeo educativo? Comunicar, 6(6). Retrieved from http://www.redalyc.org/articulo.oa?id=15800620

Bravo, L. J. (2005). Los sistemas multimedia en la enseñanza. Retrieved from http://www.ice.upm.es/wps/jlbr/Documentacion/Libros/SisteMul_05.pdf

Cabero, J. (1991). cabero_91. Retrieved October 31, 2017, from http://www.lmi.ub.es/te/any91/cabero_santander/index.html\#capitol1

Centeno, M. (2015). Propuesta de un multimedia sobre la Webquest con fines educativos para docentes del Instituto Pedagógico de Caracas. Revista de Investigación, 39(86), 39-61.

Comprar Adobe Premiere Pro CC | Software de edición y producción de vídeo. (2017). Retrieved November 1, 2017, from http://www.adobe.com/la/products/premiere.html

Consejo de Administración Legislativa (CAL). (2008). Retrieved November 8, 2017, from http://www.asambleanacional.gob.ec/es/asamblea/consejo_de_administracion_legislativa_c al

$\begin{array}{lllll}\text { Constitución } & \text { Del } & \text { Ecuador. } & \text { (2008). } & \text { Retrieved }\end{array}$ http://www.asambleanacional.gov.ec/documentos/constitucion_de_bolsillo.pdf

Curriculo - Ministerio de Educación. (2016). Retrieved November 4, 2017, from https://educacion.gob.ec/curriculo/

De Leng, B. A., Dolmans, D. H. J. M., Van De Wiel, M. W. J., Muijtjens, A. M. M., \& Van 
Der Vleuten, C. P. M. (2007). How video cases should be used as authentic stimuli in problem-based medical education. Medical Education, 41(2), 181-188. https://doi.org/10.1111/j.1365-2929.2006.02671.x

Editar Videos Gratis - Kizoa. (2017). Retrieved November 3, 2017, from https://www.kizoa.es/Editar-Videos

Editor de video de YouTube. (2017). Retrieved from https://support.google.com/youtube/answer/183851?hl=es-419

EducaLAB. (2015). 2. Tipos y momentos de evaluación. Retrieved November 14, 2017, from

http://www.ite.educacion.es/formacion/materiales/90/cd_09/cursofor/cap_4/cap4b.htm

Emma Saquinga. (2012). El uso de videos educativos y su incidencia en el aprendizaje del área de ciencias naturales de los niños y niñas de 5to año de educación básica de la escuela fiscal "Manuela Cañizares" del barrio san pedro del capulí de la parroquia San Andrés del cantón, p. 111. Retrieved from http://repo.uta.edu.ec/bitstream/123456789/5608/1/Tesisi Final.pdf

Funciones De. (n.d.). Molecular Cell. Retrieved from http://www.virtualdub.org/features.html

García, M. A. (2014). Uso Instruccional del video didáctico. Revista de Investigación, 38(81), 43-68. 4rom http://www.scielo.org.ve/scielo.php?script=sci_arttext\&pid=S101029142014000100003\&lng=es\&nrm=iso\%5Cnhttp://www.scielo.org.ve/scielo.php?script=s ci_arttext\&pid=S1010-29142014000100003

Graduación, V. I. I. S. D. E. (n.d.). Microbiológica del queso fresco en el cantón.

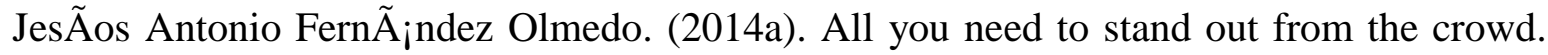
Retrieved from http://avidemux.sourceforge.net/

JesÃos Antonio FernÃ $;$ ndez Olmedo. (2014b). All you need to stand out from the crowd. $\begin{array}{llll}\text { Retrieved } \quad \text { November } & 3, & 2017, & \text { from }\end{array}$ https://www.lwks.com/index.php?option=com_content $\&$ view=article \&id=98\&Itemid=209

Larrea, O. H. (2000). Sistema de educación superior del ecuador. Sistema De Educación Superior, 1-10.

López de la Madrid, M. C. (2007). Uso de las TIC en la educación superior de México. Un estudio de caso. Revista Apertura, 7(7), 63-81. 
Marquès, P. (2000). Las TIC y sus aportaciones a la sociedad. Universidad Autónoma de de Barcelona, 2000, 1-7. Retrieved from http://fongdcam.org/manuales/educacionintercultural/datos/docs/ArticulyDocumentos/Glob aYMulti/NuevasTecno/Las Tic y sus aportaciones a la sociedad.pdf

Martín, S. (2016). El uso de las tics en la gestión empresarial. Universidad de Valladolid. Retrieved from http://uvadoc.uva.es/bitstream/10324/23407/1/TFG-O 967.pdf

Mejía Supe, C. E. (2016). Aplicaciones móviles y su relación con la difusión de información institucional de la Facultad de Ciencias Humanas y de la educación de la Universidad Técnica de Ambato cantón Ambato Provincia de Tungurahua.

Ministerio De Educacion. (2014). ¿Qué es el Buen Vivir? - Ministerio de Educación. Retrieved November 8, 2017, from https://educacion.gob.ec/que-es-el-buen-vivir/

Ministerio de Educación. (2016). Currículo de los niveles de Educación Obligatoria. Ministerio de Educación del Ecuador. Retrieved from https://educacion.gob.ec/wpcontent/uploads/downloads/2016/03/Curriculo1.pdf

Monteagudo Pedro, Sánchez Athos, H. M. (n.d.). El video como medio de enseñanza: Universidad Barrio Adentro. República Bolivariana de Venezuela. Retrieved October 4, 2017, from http://bvs.sld.cu/revistas/ems/vol21_2_07/ems06207.htm

Ojeda, N. D. (2012). Introduccion de la Multimedia. México. Retrieved from http://www.aliat.org.mx/BibliotecasDigitales/disenio_y_edicion_digital/Introduccion_a_la_ multimedia.pdf

OpenShot Video Editor ¡ iEditor de video gratuito, abierto y galardonado para Linux, Mac y Windows! (2017). Retrieved November 1, 2017, from http://www.openshot.org/

Prendes, P. (2010). Competencias Tic Para La Docencia En La Universidad Pública Española: Indicadores Y Propuestas Para La Definición De Buenas Prácticas. Informe de Proyecto EA2009-0133 de La Secretaria de Estado de Universidades E Investigación, 7-29. Retrieved from http://www.um.es/competenciastic/

ReInventar Hollywood. (n.d.). Retrieved November 1, 2017, from http://www.jahshaka.com/about/

Roblizo, M., \& Cózar, R. (2015). Usos Y Competencias En Tic En Los Futuros Maestros De Educación Infantil Y Primaria: Hacia Una Alfabetización Tecnológica Real Para Docentes. Pixel-Bit. Revista de Medios Y Educación, 47, 23-39. https://doi.org/10.12795/pixelbit.2015.i47.02 
Ros, A., \& Rosa, A. (2014). Uso del vídeo docente para la clase invertida: evaluación, ventajas e inconvenientes. Vectores de La Pedagogía Docente Actual, (24), 423-441.

Sánchez, B. J., \& Martínez, A. (2014). La Utilización De Videos Didácticos En La Enseñanza-Aprendizaje De Los Golpes De Pádel En Estudiantes Using Educational Videos in Teaching and Learning of Paddle Strokes in Students. Revista DIM (Didáctica, Innovación Y Multimedia), (10), 1-8. $\quad$ Retrieved from http://www.pangea.org/dim/revista.htm

Sancti, M., Ciencias, U. De, \& Sancti, M. (2016). Gaceta Médica Espirituana medical sciences careers, 18(3).

Sarmiento, M. A., May, N. K., Cadena, M., \& Casanova, J. (2015). La Elaboración del Video como Recurso De Aprendizaje En la Enseñanza del Idioma Inglés en el nivel medio superior de la Universidad Autónoma De Campeche. Revista Iberoamericana de Producción Académica Y Gestión Educativa, 1-16. Retrieved from http://www.pag.org.mx/index.php/PAG/article/view/378/416

SENPLADES, S. N. de P. y D. (2013). El Socialismo del Buen Vivir - Plan Nacional 2013 - 2017. El Socialismo Del Buen Vivir - Plan Nacional 2013 - 2017. Retrieved from http://www.buenvivir.gob.ec/el-socialismo-del-buen-vivir

Software de edición de video de Corel - VideoStudio Pro X10. (2017). Retrieved November 1, 2017, from https://www.videostudiopro.com/en/products/videostudio/pro/

Summary, E. (2015). Table of Contents.

Tunnermann, C. (2008). La calidad de la educacion superior y su acreditacion: La experiencia Centroamericana. Revista Da Avaliação Da Educação Superior, 13, 313-336. https://doi.org/10.1590/S1414-40772008000200005

Upcott, L., Rickeston, L., Kinving, K., \& Sullivan Gillian. (2017). PowToon | Create Animated Videos for Work or Play. Retrieved November 3, 2017, from https://www.powtoon.com/home/g/es/

Velarde, A., Dehesa, J. M., López, E., \& Márquez, J. (2017). Los vídeo tutoriales como apoyo al proceso de enseñanza apr. EDUCATECONCIENCIA, 14(15).

Video Editor \&amp; Video Editing Software | Camtasia | TechSmith. (1995). Retrieved November 1, 2017, from https://www.techsmith.com/video-editor.html

VideoPad, editor de vídeo. (n.d.). Retrieved November 1, 2017, from http://www.nchsoftware.com/videopad/es/index.html\#101 
WeVideo | Editor de video en línea para web, móvil, Windows y OSX. (2017). Retrieved November 3, 2017, from https://www.wevideo.com/

Windows Movie Maker Descargar -Para Windows 7/8/10/Xp/Vista. (2016). Retrieved November 1, 2017, from http://www.windows-movie-maker.org/es/

Yela, S. (2011). Herramientas de evaluación en el aula. Retrieved from http://www.usaidlea.org/images/Herramientas_de_Evaluacion_2011.pdf\%0Awww.minedu c.gob.gt

Zerquera, J., Hernández, S., Delgado, H., Romeu, M., Valdés, M., Hernández, P., ... Alemañy, J. (2015). Multimedia para profesores y estudiantes de 5to año de medicina. Asignatura Salud Pública. Medisur, 13(2), 254-274. Retrieved from http://scielo.sld.cu/scielo.php?script=sci_arttext\&amp\%5Cnpid=S1727897X2015000200007

Rev. G.B. (2010). ¿Qué es educar?. Que es educación (pp. 3-4). Argentina: AuthorHous

Herbert, Z. (2009). Manual de producción de televisión. Querétaro: Imagen Editorial

Mónica, G.G \& Myrthala, V.B. (2008). La preproducción. Producción de televisión (pp. 97-111). México: Trillas

Mónica, G.G \& Myrthala, V.B. (2008). La producción. Producción de televisión (pp. 123135). México: Trillas

Mónica, G.G \& Myrthala, V.B. (2008). La posproducción. Producción de televisión (pp. 143-151). México: Trillas

Santiago, C.V. (2015). Capitulo 6. El proyecto. Arte y gestión de la producción audio visual (pp. 31-34). Colombia: UPC

Paúl, P. (1976). Diccionario de Pedagogía. España: oikos-taus

Vicente, S.L. (2012). Diseño curricular a partir de competencias. Colombia: Ediciones de la $\mathrm{U}$

Alexander, O.O. (2014). Currículo y Didáctica. Colombia: Ediciones de la U

Eduardo, P.C. (2013). Estrategias docentes con tecnologías. Guía práctica. México: Pearson

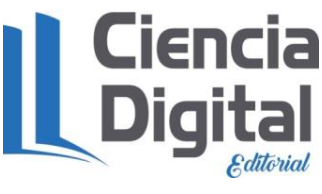


Para citar el artículo indexado.

Salazar J., Sánchez E., Velasteguí E. \& Núñez S., (2018). El video como estrategia didáctica en la educación superior. Revista electrónica Ciencia Digital 2(2), 29-47. Recuperado desde:

http://cienciadigital.org/revistacienciadigital2/index.php/CienciaDigital/article/view/71/66

El artículo que se publica es de exclusiva responsabilidad de los autores y no necesariamente reflejan el pensamiento de la Revista Ciencia Digital.

El articulo queda en propiedad de la revista y, por tanto, su publicación parcial y/o total en otro medio tiene que ser autorizado por el director de la Revista Ciencia Digital.
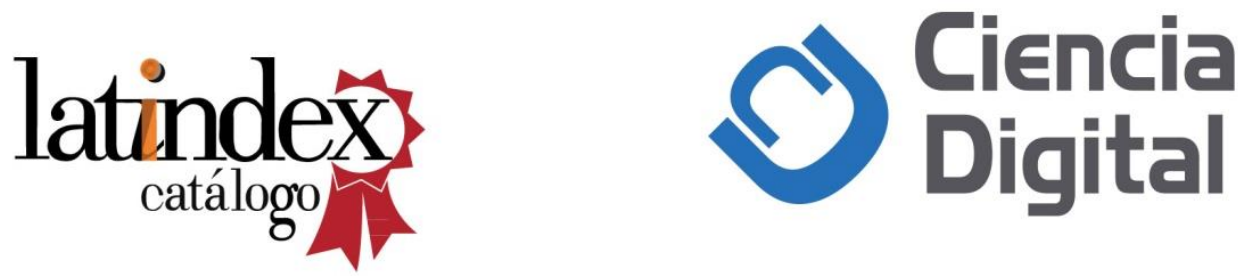